\title{
A prática Argumentativa Geométrica: da Intuição à Lógica Dedutiva
}

\author{
The Geometrical Argumentative Practice: from Intuition to Deductive Logic
}

\author{
Sabrina Alves Boldrini \\ sabrinaboldrinicabral@hotmail.com
}

Eliane Scheid Gazire

e.gazire@terra.com.br

\begin{abstract}
Resumo
Este artigo descreve parte de uma pesquisa realizada com 17 alunos do terceiro ano do Ensino Médio da rede pública de ensino da Escola Estadual Prefeito Jaime Toledo, localizada no município de Caiana, no estado de Minas Gerais. A pesquisa foi realizada com intuito de verificar, de acordo com o modelo proposto por Balacheff (1987), o nível de prova geométrica encontrado nas argumentações desses alunos diante da necessidade de justificar uma determinada situação proposta; bem como analisar se partindo de uma atividade de prova experimental é possível que esses alunos desenvolvam uma melhor compreensão de uma determinada propriedade geométrica. Para a construção do experimento, utilizamos a atividade Engenharia de Grego adaptada do portal $\mathrm{M}^{3}$ Matemática Multimídia da UNICAMP. Os resultados obtidos mostram que as argumentações construídas encontram-se em um tipo de prova Pragmática, variando entre Empirismo Ingênuo e Exemplo Genérico e que a ausência de uma linguagem matemática mais avançada nessas argumentações está relacionada à falta de maturidade matemática. Verificamos, também, que a atividade proposta contribuiu de forma significativa na construção dos conceitos geométricos apresentados.
\end{abstract}

Palavras-chave: Intuição; Prova experimental; Argumentação geométrica; Dedução.

\begin{abstract}
This article describes part of a research carried out with 17 students from the third high school of the Public School of Education of the State School Prefeito Jaime Toledo, located in the municipality of Caiana, in the state of Minas Gerais. The research was carried out in order to verify, according to the model proposed by Balacheff (1987), the level of geometric evidence found in the arguments of these students in view of the need to justify a certain proposed situation; As well as to analyze if starting from na activity of experimental proof is possible that these students develop a better understanding of a certain geometric property. For the construction of the experimente we used the activity of Greek adapted from the portal $\mathrm{M}^{3}$ Multimedia Mathematics of UNICAMP. The results show that the constructed arguments are in a type of Pragmatic proof, varying between Naive Empiricis mand Generic Example, and that the absence of a more advanced mathematical language in these arguments is related to the lack of mathematic maturity. We also verified that the proposed activity contributed significantly to the construction of the presented geometric concepts.
\end{abstract}

Keywords: Intuition; Experimental test; Geometric argumentation; Deduction.

\section{Introdução}

Desde os tempos mais antigos, os indivíduos relacionam os acontecimentos de determinados fatos à sua intuição. Exprimem sentimentos e opiniões individuais e de grupos, variando de acordo com as condições por eles vivenciadas. Agrupam ou distinguem as coisas e fatos de forma intuitiva, através das semelhanças ou diferenças perceptíveis. 
A construção do pensamento humano alicerça-se na experiência cultural e social do homem, que, a partir de sua concepção de mundo, busca explicações para a realidade na qual está inserido. A construção do pensamento é feita pela leitura daquilo que foi armazenado na memória. Desse armazenamento, o ser humano constrói as suas teorias para explicar experiências realizadas e discutir conceitos a partir de observações e análises, sistematizando, assim, o seu conhecimento.

Pensando na evolução e história da humanidade, pode-se perceber que todo o seu processo de desenvolvimento está fundamentado na edificação do conhecimento humano, que, ao longo dos tempos, foi transmitido de várias formas às gerações com intuito de melhorar a vida em sociedade.

A construção do conhecimento, no sentido de aprendizagem, tem sido, durante muito tempo, objeto de pesquisa em vários ramos das ciências que, cada vez mais, se ocupam em tentar compreendê-la. Teóricos como Piaget ${ }^{1}$ e Vygotsky ${ }^{2}$ atribuem o processo de desenvolvimento individual do conhecimento à influência dos meios sociais, históricos e culturais e do indivíduo sobre esses.

Para ambos teóricos, a aprendizagem é o processo pelo qual o indivíduo adquire informações, habilidades, atitudes e valores a partir de seu contato com a realidade, com os objetos, com o meio ambiente e com outras pessoas. A aprendizagem é condição necessária e essencial do desenvolvimento potencial do sujeito e tem influência direta no processo de construção do seu conhecimento.

E nesse processo de construção do conhecimento humano, o saber Geométrico apresenta-se como ponto de partida, pois reflete seu conhecimento acerca do mundo, explorando questões que permitem ao homem pensar e repensar suas práticas, buscando cada vez mais por um novo conhecimento, que muitas vezes não se faz aplicável à prática cotidiana de sua época, mas que pode se fazer útil e necessário em tempos futuros.

\section{Intuição x Dedução}

De acordo com o dicionário Aurélio (FERREIRA, 2010, p. 523), a palavra intuição significa: 1-percepção instintiva; 2- conhecimento imediato; 3- pressentimento da verdade. A filosofia a define como forma de contato direto ou imediato da mente com o real, capaz de

\footnotetext{
${ }^{1}$ Piaget- A compreensão dos mecanismos de constituição do conhecimento, na concepção de Piaget, equivale à compreensão dos mecanismos envolvidos na formação do pensamento lógico-matemático. A lógica representa, para Piaget, a forma final do equilíbrio das ações. (Fonte: O desenvolvimento do pensamento "Equilibração das estruturas cognitivas”. Lisboa: Publicações Dom Quixote, 1977).

${ }^{2}$ Vygotsky - Enfatiza o processo histórico-social e o papel da linguagem no desenvolvimento do indivíduo. Sua questão central é a aquisição de conhecimentos pela interação do sujeito com o meio. Para o teórico, o sujeito é interativo, pois adquire conhecimentos a partir de relações intra e interpessoais e de troca com o meio, a partir de um processo denominado mediação. (Fonte: Pensamento e Linguagem. Rio de Janeiro: Martins Fontes, 1998). 
captar sua essência de modo evidente, mas não necessitando de demonstrações. Assim, para a filosofia, o termo intuição serve tanto para as interpretações do senso comum, quanto para o desenvolvimento do pensamento intelectual.

Na história da filosofia, segundo Chauí (2000), os dois exemplos mais célebres de intuição intelectual encontram-se em Platão [século IV a.C.] e em Descartes [século XVII].

Na narrativa do Mito da Caverna ${ }^{3}$, Platão [século IV a.C.] conta o que se passa com um prisioneiro que, ao sair da escuridão da caverna, vê a luz do Sol e, em lugar de sombras, vê as próprias coisas. Nessa passagem, Platão [século IV a.C.] compara o prisioneiro ao filósofo que, ao fazer o percurso do conhecimento, vê a luz do "Bem" e contempla as ideias verdadeiras.

O prisioneiro tem uma intuição empírica, pois tudo que conhece, conhece por sensação ou por percepção sensorial. O filósofo, por sua vez, tem uma intuição intelectual, pois, é seu intelecto ou sua inteligência que conhece as ideias verdadeiras. No entanto, o conhecimento de ambos é intuitivo porque é direto, imediato, sem necessidade de demonstrações, argumentos e provas.

O filósofo francês Descartes [século XVII], em sua obra intitulada Discurso do Método ${ }^{4}$ que ficou conhecida como Cogito Cartesiano: "Cogito, ergo sum”, (Penso, logo existo), descreve a intuição intelectual como um conhecimento intuitivo. Segundo o autor, "quando penso, sei que estou pensando e não preciso, dessa forma, provar ou demonstrar isso" (DESCARTES, 2001, p. 17). Trata-se de intuição intelectual por ser realizada exclusivamente pelo intelecto ou pela inteligência que capta, em um único ato, a verdade do pensamento.

Na concepção de ambos, a intuição é uma compreensão completa ou imediata de um objeto, de um fato. Nela, a razão capta todas as relações que constituem a realidade e a verdade do objeto intuído. É um ato intelectual de discernimento e compreensão, sem necessidade de provas ou demonstração para saber o que se conhece.

Na Crítica da razão Pura, para Kant (2001), a intuição é uma forma "a priori” da sensibilidade, constituindo, com o entendimento, as condições de possibilidade do conhecimento. Assim, são duas as intuições: de espaço e de tempo relacionadas por Kant (2001) à Geometria Euclidiana. Espaço e tempo constituem o caminho verdadeiro para o

${ }^{3}$ O Mito da Caverna, também conhecido como "Alegoria da Caverna" é uma passagem do livro "A República" do filósofo grego Platão. (A República; São Paulo: Nova Cultura, 2000. 352 pag. Tradução de Enrico Corvisiere).

4 O Discurso do Método - "Penso, logo existo": tal proposição resume o espirito de René Descartes (15961650), sábio francês, cujo O Discurso do Método inaugurou a filosofia moderna. 
processamento e a conceitualização de uma "coisa" possibilitando a unificação do sensível e a recepção das percepções. Segundo Kant (2001, p.89), "não podemos pensar em algo que não esteja nem no espaço, nem no tempo: os pensamentos sem conteúdo são vazios, as intuições sem conceitos são cegas".

A intuição pode depender de conhecimentos anteriores e ocorre quando esses são percebidos de uma só vez, numa síntese em que aparecem articulados e organizados num todo: em sua forma, seu conteúdo, suas causas, suas propriedades, seus efeitos e suas relações com os outros.

No que diz respeito aos pensamentos filosóficos, a intuição pode ser o ponto de chegada, a conclusão de um processo de conhecimento, mas também pode ser o ponto de partida desse mesmo processo. Nesses dois casos, o processo cognitivo constitui a razão discursiva ou o raciocínio.

Ao contrário da intuição, o raciocínio é o conhecimento que exige provas e demonstrações das verdades conhecidas ou investigadas. Não é apenas um ato intelectual, mas sim vários atos intelectuais conectados com o objetivo de formar todo um processo de conhecimento. Trata-se de um exame de vários sinais que permitem a um indivíduo fazer inferências, ou seja, tirar conclusões com base em algum objeto do seu conhecimento ou em dados já conhecidos.

De acordo com a corrente do pensamento estruturalista, cada campo do conhecimento tem seu método próprio de estruturar o raciocínio. Por exemplo, quando o raciocínio é construído, seja por critérios de generalidade ou universalidade, tem-se a dedução.

A dedução é um método de estruturação do pensamento que Husserl [1859 - 1938] relaciona à Matemática. Segundo ele, a dedução consiste em partir de uma verdade já conhecida e que funciona como um princípio geral ao qual se subordinam todos os casos que serão demonstrados a partir dela. Assim, permite que cada novo caso particular seja conhecido, demonstrando que a ele se aplicam todas as leis, regras e verdades da teoria.

De acordo com Chauí (1995), nossa ideia de verdade foi construída ao longo dos séculos a partir de três concepções diferentes: da linguagem grega (aletheia) - nessa concepção a verdade é uma qualidade das próprias "coisas", ou seja, a verdade está naquilo que pode ser visto e o conhecimento verdadeiro é a percepção intelectual ou racional dessa verdade; da linguagem latina (veritas) - concepção que se refere à precisão, ao rigor e a exatidão, assim, o critério da verdade é dado pela validade lógica de seus argumentos; e da linguagem hebraica (emunah) - nessa concepção, a verdade é uma crença fundada na esperança e na confiança de algo que vai acontecer. 
Nesse caso, considera-se que a verdade depende de um acordo ou de um conjunto de convenções universais que devem ser respeitadas por todos, ou seja, um consenso. O que se pretende, através do raciocínio dedutivo, é alcançar a verdade lógica de uma proposição, ou seja, dispor da “demonstração" desse raciocínio, partindo de argumentos já provados.

A demonstração de uma proposição é algo que tem um significado bem determinado: saber se tal proposição é verdadeira. "A demonstração é uma cadeia de definições, já que a explicação de uma palavra é a sua definição e a explicação de uma proposição que consiste em um conjunto de definições é igual a sua demonstração". (LEIBNIZ, 1686 apud MARK, p. 197, 2013).

De acordo com Aristóteles [384 a.C - 322 a.C] no livro Segundos Analíticos, "o conhecimento demonstrativo deve descansar em verdades básicas necessárias (razão), porque o objeto do conhecimento científico não pode ser distinto do que é" (ARISTÓTELES, 2004, p.74). Nesse aspecto, a demonstração é um método racional de conhecimento que deve ser rigoroso e tal rigor depende das "premissas" que são o ponto de partida de todo argumento.

O conhecimento racional constitui uma verdade necessária encontrada através de sua "decomposição" em ideias e verdades cada vez mais simples, até alcançar uma verdade primitiva (princípio). Assim, qualquer fato ou enunciado deve ter uma "razão" ou uma causa determinante para existir. Essas verdades elementares, que radicam a razão suficiente, são as Definições, os Axiomas e os Postulados: "princípios primitivos e evidentes" que não necessitam de provas ou demonstrações.

O pensamento lógico ou racional opera de acordo com os Princípios da Identidade, da Não Contradição, do Terceiro Excluído, da Razão Suficiente e da Causalidade que distinguem verdades de fato e verdades de razão; diferenciam intuição e dedução considerando o conhecimento verdadeiro como o conhecimento de suas causas.

\section{O Pensamento Geométrico}

Os seres humanos sempre foram movidos por um grande desejo de entender o mundo que os cerca. Seus esforços para encontrar bem a fundo o significado de todas as coisas estão relacionados à necessidade de buscar melhorias para sua sobrevivência e as razões que fundamentam a complexidade percebida de todo o universo estão relacionadas ao conhecimento. Assim, os conhecimentos começam com as experiências vividas e as percepções acerca do universo estão relacionadas à maneira pela qual se associa o mundo percebido às ideias. 
Sabe-se que o conhecimento geométrico não nasceu de um sistema constituído de Teoremas demonstrados por raciocínios lógicos a partir de alguns princípios básicos. A produção do conhecimento nesse ramo da Matemática aponta que suas utilidades práticas estão relacionadas a algumas necessidades da vida humana.

Segundo Rooney (2012), os primeiros contatos humanos com a Geometria são anteriores aos sistemas de números escritos: “[...] muitos povos antigos deixaram evidências de seu interesse por padrões repetidos, simetrias e formas na forma de padrões geométricos decorando seus objetos, estruturas e residências". (ROONEY, 2012, p.73). O O homem neolítico, por exemplo, em seus desenhos e figuras, mostra uma preocupação com as relações espaciais. Seus potes, tecidos e cestas apontam uma noção bastante relevante de simetria e congruência. Para Fetissov (1994), a primeira noção geométrica a se desenvolver nas civilizações foi a noção de distância, questão que certamente envolve a "ideia" de linha reta. Em seguida, a noção de forma circular e a diferença entre "um e muitos".

Com o nascimento das primeiras sociedades e o surgimento da agricultura que proporcionava aos homens uma existência sedentária (habitação fixa), outras manifestações geométricas são percebidas no desenvolvimento das civilizações, entre elas, capacidades de medir distâncias, áreas, volumes e tempo.

Documentos de aproximadamente 3100 a.C. revelam que os egípcios e babilônios já possuíam algumas regras matemáticas para medir recipientes de armazenamento, medir extensões de terrenos e planejar construções. Segundo Boyer (1996), a regra egípcia para achar a área do círculo tem sido considerada um dos maiores sucessos da época:

No problema Geométrico número 50, o escriba Ahames ${ }^{5}$ assume que a área de um campo circular com diâmetro de nove unidades é a mesma de um quadrado com lado oito unidades. Comparando com a fórmula moderna $A=\pi r^{2}$ vemos que a regra egípcia equivale a atribuir a $\pi$ o valor $31 / 6$ é uma aproximação bastante elogiável [...]. (BOYER, 1996, p. 12).

Para Boyer (1996), essa observação representa uma relação geométrica muito mais precisa e matematicamente significativa do que uma aproximação relativamente boa para o $\pi$. "O que importa aqui é a percepção das inter-relações entre as figuras geométricas” (BOYER, 1996, p. 12).

\footnotetext{
${ }^{5}$ Muitas informações sobre a matemática egípcia vem do Papiro de Rhind ou de Ahmes, o mais extenso documento matemático do Antigo Egito. Com cerca de $0,30 \mathrm{~m}$ de altura e $5 \mathrm{~m}$ de comprimento é assim conhecido em honra ao escriba que o copiou por volta de 1650 a.C. Hoje esse documento pertence ao British Museum (exceto uns poucos fragmentos que estão no Brookliyn Museum. (BOYER, 1996).
} 
Relacionar entre si observações geométricas que tinham em comum algumas propriedades, era uma metodologia empregada pelos egípcios, que se embasavam em procedimentos empíricos (sem justificativas ou demonstrações) para desenvolver um pensamento geométrico. Mas ainda que essas culturas tenham produzido uma geometria reconhecível, faltava-lhe o caráter sistemático, rigoroso, puro, ou seja, não empírico.

Aos poucos, foram surgindo algumas leis geométricas pelas quais o homem passava a guiar-se em questões cuja natureza se adequava a elas. O pensamento geométrico passa de uma coleção de noções desconexas sobre o espaço físico para uma fase de maior abstração. Nesse momento, os argumentos indutivos criam um exercício para o pensar cujo caminho é percorrido a partir de observações particulares do objeto investigado, tomadas a priori como verdadeiras em busca de uma generalização conceitual da verdade observada.

Assim, os conceitos tornam-se necessários e o conhecimento a respeito de um determinado objeto torna-se mais preciso. Os homens aumentam seus esforços para compreender a fundo o significado de todas as coisas. Passam a buscar padrões que fundamentem a complexidade percebida do universo, novas ciências surgem e a geometria se desenvolve consideravelmente.

De maneira intencional, são elaboradas organizações estruturais que sustentam a compreensão das experiências vividas, permitindo que esses atos sejam formalizados e categorizados de uma maneira um pouco mais complexa.

Segundo Bicudo,

Os modos de objetivação científica que tecem as camadas da construção do conhecimento geométrico estão nuclearmente ligados aos modos de eles próprios serem expressos. Significa que o percebido vai sendo construído como objetividade em concomitância com os modos linguísticos que os expressam, e vice-versa. (BICUDO, 2010, p. 142).

O exercício do pensamento geométrico pela razão cria uma operação na qual o conhecimento sobre determinado objeto parte de leis universais, que supostas constituem as premissas do pensamento racional e quando deduzidas, chegam à conclusão elevando esse conhecimento a um caráter mais geral com uma perspectiva mais reflexiva.

É nesse âmbito que o pensamento geométrico se constitui, partindo do estudo das propriedades do mundo material através do pensamento intuitivo que constitui a atividade prática (experimentação) do homem elevando-se à descoberta das verdades geométricas (demonstração). 


\section{A Atividade de prova experimental: da Intuição à Lógica Dedutiva}

Ao iniciarmos o segundo bimestre do ano letivo, no mês de abril, o conteúdo a ser trabalhado com a turma do terceiro ano "A" proposto pelo planejamento anual de acordo com os Conteúdos Básicos Comuns ${ }^{6}$ (MINAS GERAIS, 2006) de Matemática para o Ensino Médio, propunha o estudo de alguns tópicos de Geometria Analítica, dentre eles: o estudo do ponto e da reta, bem como algumas de suas principais propriedades, como: distância entre dois pontos, condição de alinhamento entre três pontos, ponto médio de um segmento e a equação geral da reta.

O objetivo desse estudo é desenvolver no aluno a capacidade de compreender e utilizar o pensamento geométrico a fim de que possa resolver situações-problema de localização e deslocamento, reconhecendo as noções de direção e sentido, de ângulo, de paralelismo e de perpendicularismo.

Procurando relacionar o conteúdo a ser trabalhado com a turma e o objetivo de nossa pesquisa, optamos por iniciar esse estudo partindo de uma atividade experimental, que, de acordo com Alves (2002), deve ser entendida como um "objeto didático", ou seja, o produto de uma Transposição Didática capaz de agregar características de versatilidade e contribuir de forma mais significativa para o processo de ensino-aprendizagem. Assim, estruturamos nossa aula com base no experimento "Engenharia de Grego".

Adaptado do portal $\mathrm{M}^{3}$ Matemática Multimídia da UNICAMP, o experimento Engenharia de Grego tinha, como principal objetivo, desenvolver nos alunos a capacidade de planejar, construir e avaliar um projeto, bem como aplicar conceitos básicos de geometria analítica na solução de um problema de construção civil.

Seguindo uma sequência didática que nos parecia mais coerente, introduzimos o assunto proposto para aquela aula fazendo uma explanação geral sobre o conteúdo que iríamos abordar. Com o auxílio do livro didático "Matemática: Ciências e Aplicações” (IEZZI et al., 2014), adotado pela escola para o terceiro ano do Ensino Médio, apontamos alguns fatos do cotidiano nos quais são aplicados alguns conceitos básicos da Geometria Analítica. Após fazermos essa introdução, organizamos os dezessete (17) alunos presentes naquele dia em grupos, obtendo, assim, três grupos com quatro integrantes cada e um grupo com cinco.

\footnotetext{
${ }^{6} \mathrm{CBC}$ - proposta curricular que estabelece os conhecimentos, as habilidades e competências a serem adquiridos pelos alunos na Educação Básica, bem como as metas a serem alcançadas pelo professor a cada ano nas escolas da rede pública Estadual de Minas Gerais. A definição dos Conteúdos Básicos Comuns (CBC) para os anos finais do Ensino Fundamental e para o Ensino Médio constitui um passo importante no sentido de tornar a rede estadual de ensino de Minas um sistema de alto desempenho.

${ }^{7} \mathrm{O}$ experimento "Engenharia de Grego" foi adaptado do portal educacional $\mathrm{M}^{3}$ Matemática Multimídia que contém recursos educacionais multimídia em formatos digitais desenvolvidos pela Unicamp com financiamento do FNDE, SED, MCT e MEC para o Ensino Médio de Matemática no Brasil.
} 
Na etapa seguinte, o problema foi dado aos alunos, sem antes explanarmos qualquer definição ou conceito do conteúdo abordado:

Encontrar uma maneira de projetar um túnel que será construído partindo ao mesmo tempo de dois pontos fixados no contorno de uma montanha.

O problema apresentado foi escolhido como forma de se observar a possibilidade de os alunos utilizarem conceitos matemáticos anteriormente adquiridos como base para resolução da situação proposta. Acreditamos que essa contextualização seja muito importante na abordagem com o aluno, pois este demonstra mais interesse quando o conteúdo é apresentado dessa forma.

Prosseguimos o experimento orientando aos alunos que realizassem os seguintes procedimentos a fim de que pudessem representar graficamente a situação dada:

Coloque uma cartolina em um local plano; sobre ela coloque uma mochila que irá simular a montanha; faça o contorno da montanha e marque nesse contorno dois pontos que serão as extremidades do túnel. Anote todas as estratégias que irão utilizar para realizar a tarefa.

Explicamos apenas o que deveria ser feito para representar a situação proposta, de forma que os alunos pudessem discutir ideias, justificativas, estratégias e argumentos para formulação da solução do problema. Percebemos, nesse momento, muita interação entre os componentes dos grupos. Notamos que todos estavam empenhados em determinar estratégias para solucionar a situação proposta como mostra figura 1.

Figura 1: Alunos desenvolvendo a primeira etapa do experimento

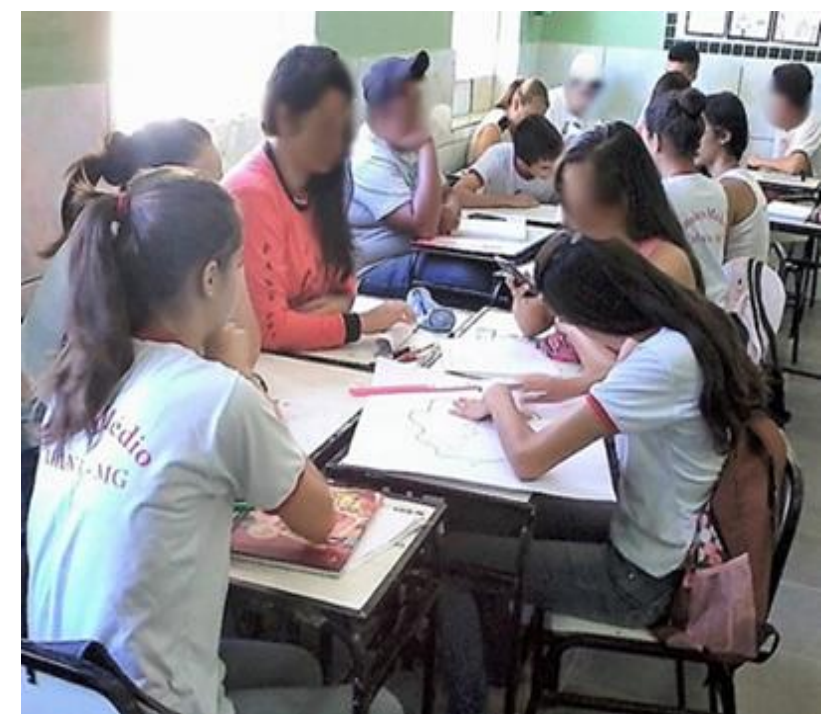

Fonte: Dados da pesquisa. 
Na sequência, os alunos deveriam planejar como escavar a montanha de forma que as escavações se encontrassem num mesmo ponto. Esperávamos, nessa etapa, que eles utilizassem alguns conceitos de geometria para decidir em que direção iniciar as escavações em cada uma das extremidades do túnel.

Como não haviam recebido nenhuma sistematização sobre o conteúdo, todos os grupos tiveram muita dificuldade em estabelecer o critério que iriam seguir para resolver o problema proposto. Muitos se queixavam por não saber qual "fórmula" deveriam utilizar para resolver o problema, como pode ser constatado nas transcrições de algumas falas desses alunos:

Aluno A: "Professora, qual fórmula nós temos que usar para resolver o problema?

Aluno B: "Professora, em qual página do livro eu encontro a fórmula para resolver essa atividade?

Aluno C: "Não temos como resolver o problema, pois a senhora ainda não explicou essa matéria."

De acordo com Nasser e Tinoco (2003), essas manifestações revelam que quando desafiados a resolver uma determinada situação-problema, os alunos se limitam a usar um argumento de "autoridade", na maioria das vezes, pelo motivo de não terem sido acostumados a investigar. Assim, ficam esperando que o professor determine quais estratégias devem seguir para chegar à solução do problema proposto.

Esses tipos de questionamentos nos remetem à ideia de que o trabalho com a Matemática enfatiza sempre um conhecimento finalizado, pronto para ser transmitido, ou seja, uma relação ensinar-aprender, em que o professor é aquele que sabe e o aluno deve aprender aceitando passivamente o discurso do professor.

Segundo Hanna (2000), a ocorrência desse tipo de comportamento está relacionada ao fato de os alunos estarem acostumados a lidar com atividades sequenciadas, abordadas sempre de forma mecanizada. Para a pesquisadora, essa abordagem faz com que a Matemática seja trabalhada pela Matemática em si mesma, sem considerar a possibilidade de oferecer ao aluno uma vivência das ideias matemáticas de forma que possa compreendê-las.

Consideramos que os conceitos matemáticos são formados pela ação interiorizada do aluno, pelo significado que dão às formulações que enunciam e às verificações que realizam. Nessa perspectiva, tendo em vista os questionamentos feitos pelos grupos, para que se sentissem mais "livres" na investigação da situação proposta, julgamos ser necessário fazer uma intervenção, a fim de esclarecer que eles deveriam criar seus próprios métodos de resolução.

"Não tem uma fórmula exata. Vocês devem escolher os procedimentos que irão seguir para solucioná-lo. Analisem o problema e construam estratégias para tentar solucioná-lo da maneira que acharem mais conveniente". (PROFESSORA, dados da pesquisa). 
Após essa intervenção, percebemos que os alunos sentiram-se mais seguros para assumir e defender posicionamentos, tomar decisões e formular estratégias para tentar solucionar o problema proposto.

De acordo com Nasser e Tinoco (2003, p.56), “é sempre recomendável ouvir o aluno para bem compreender a sua maneira de pensar". Quando esse é convidado a manifestar sua forma de pensar, maior será a possibilidade de aprendizagem, pois o aluno participa da busca por "significar" as ideias trabalhadas. Nesse sentido, prosseguimos o experimento, sempre nos preocupando em identificar possíveis concepções espontâneas ou explicações prévias dadas por eles.

A cada etapa do processo, procurávamos saber o que os alunos esperavam com a realização dessa atividade. À medida em que propunham suas próprias interpretações para a situação, procurávamos reunir essas ideias no quadro.

Entendemos que essas discussões em grupo e no grupo contribuíram para que os alunos tivessem oportunidade de expor suas opiniões. Percebemos, também, que eles sentiram-se motivados e desafiados a participar desse processo. No decorrer dessas discussões, recebemos de um determinado grupo, denominado aqui por grupo 01, uma contribuição bastante interessante em relação ao problema proposto:

Grupo 01: Para determinarmos a direção em que as equipes deverão escavar precisamos saber onde cada equipe está localizada. Se traçarmos um plano cartesiano, poderemos encontrar as coordenadas dos pontos $A$ e $B$ que se encontram nas extremidades da montanha $e$ assim determinar a distância entre eles. Depois é só encontrarmos o ponto médio desse segmento e assim saberemos o local de encontro das duas equipes.

Figura 2: Modelo proposto pelo grupo 01

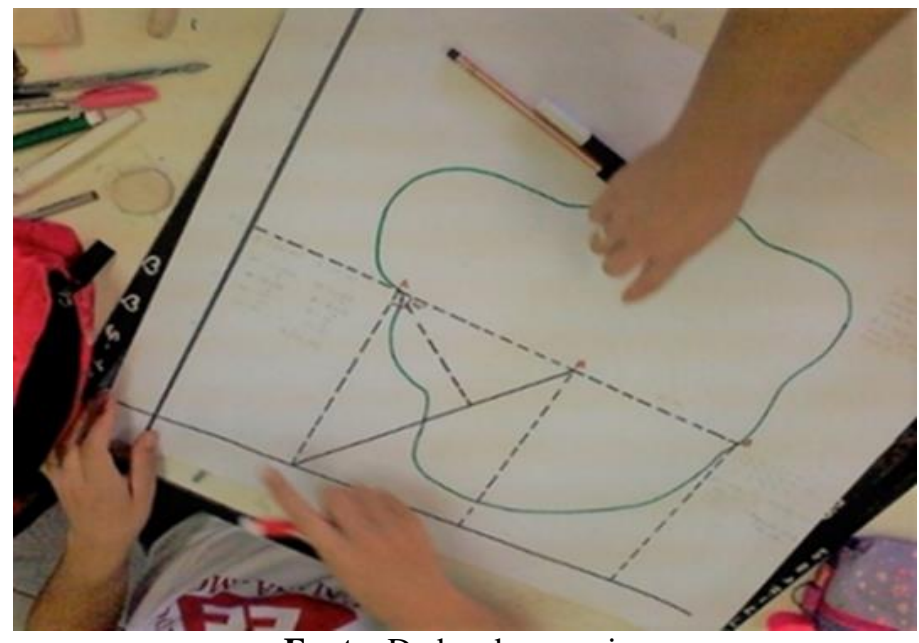

Fonte: Dados da pesquisa 
Nesse momento, observamos que, ao se envolverem com a tarefa de verificar a distância entre as extremidades da montanha, com o propósito de determinar as coordenadas dos pontos A e B, o grupo 01 traçou as estratégias que seguiriam para solucionar o problema.

Esse ato propicia o estabelecimento de uma relação com o saber, pois, na tentativa de solucionarem o problema, os alunos recorreram a conhecimentos adquiridos anteriormente e que julgavam ser suficientes para solucionar a situação proposta.

Figura : Estratégias apresentadas pelo grupo 01 para solucionar a situação proposta

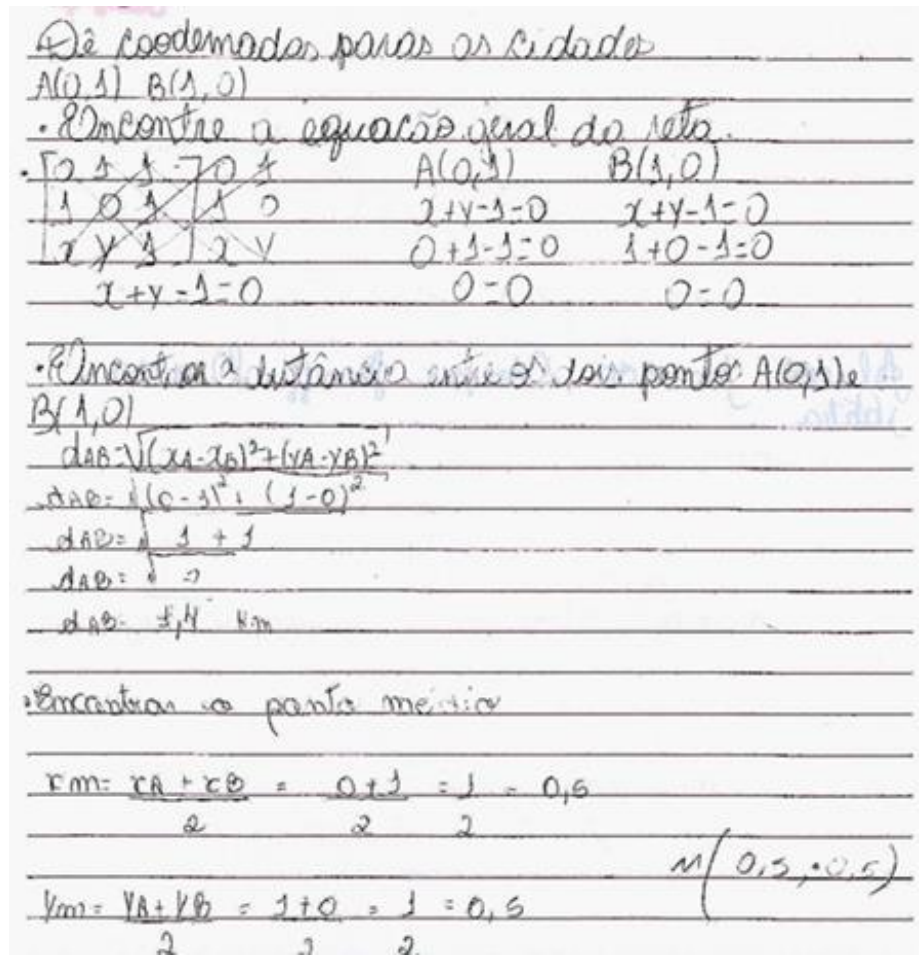

Fonte: Dados da pesquisa.

Ao focalizarmos a atividade desenvolvida, constatamos que as ideias utilizadas para solucionar o problema fazem parte de uma habilidade mental do aluno que lhe permite reconhecer e identificar algumas relações matemáticas, o que, de acordo com Nasser e Tinoco (2003), está diretamente ligada à capacidade de justificar conceitos.

Considerando a importância da construção do conhecimento, vemos, nos argumentos construídos pelos alunos, um grande valor educacional, pois, ao determinar as estratégias que seguiriam para solucionar a situação proposta, eles trabalharam com afirmações que descreviam, de maneira bastante próxima, uma situação vivida expressa numa linguagem matemática estruturada e formalizada de acordo com a sua percepção.

Analisando as estratégias construídas pelo grupo e a solução apresentada para o problema, verificamos que, de acordo com Balacheff (1987), o tipo de argumentação utilizada 
pelos alunos para provar o resultado obtido é conhecida como "Prova Pragmática" e classificada como "Empirismo Ingênuo". Nesse tipo de prova, o aluno tira suas conclusões a respeito de uma determinada situação a partir de um pequeno teste que realiza.

Nessa caracterização, fica implícita a ideia de que, ao desenvolverem estratégias para solucionar uma determinada situação dada, os alunos não se preocupam em demonstrar esse fato como uma verdade matemática. Assim, buscam apenas encontrar resultados, que, na maioria das vezes, apresentam-se de forma bastante empírica, mas que, de certa forma, consideram solucionar o problema, como pode ser notado, também, na solução apresentada pelo grupo 04.

Figura 4: Solução proposta pelo grupo 04

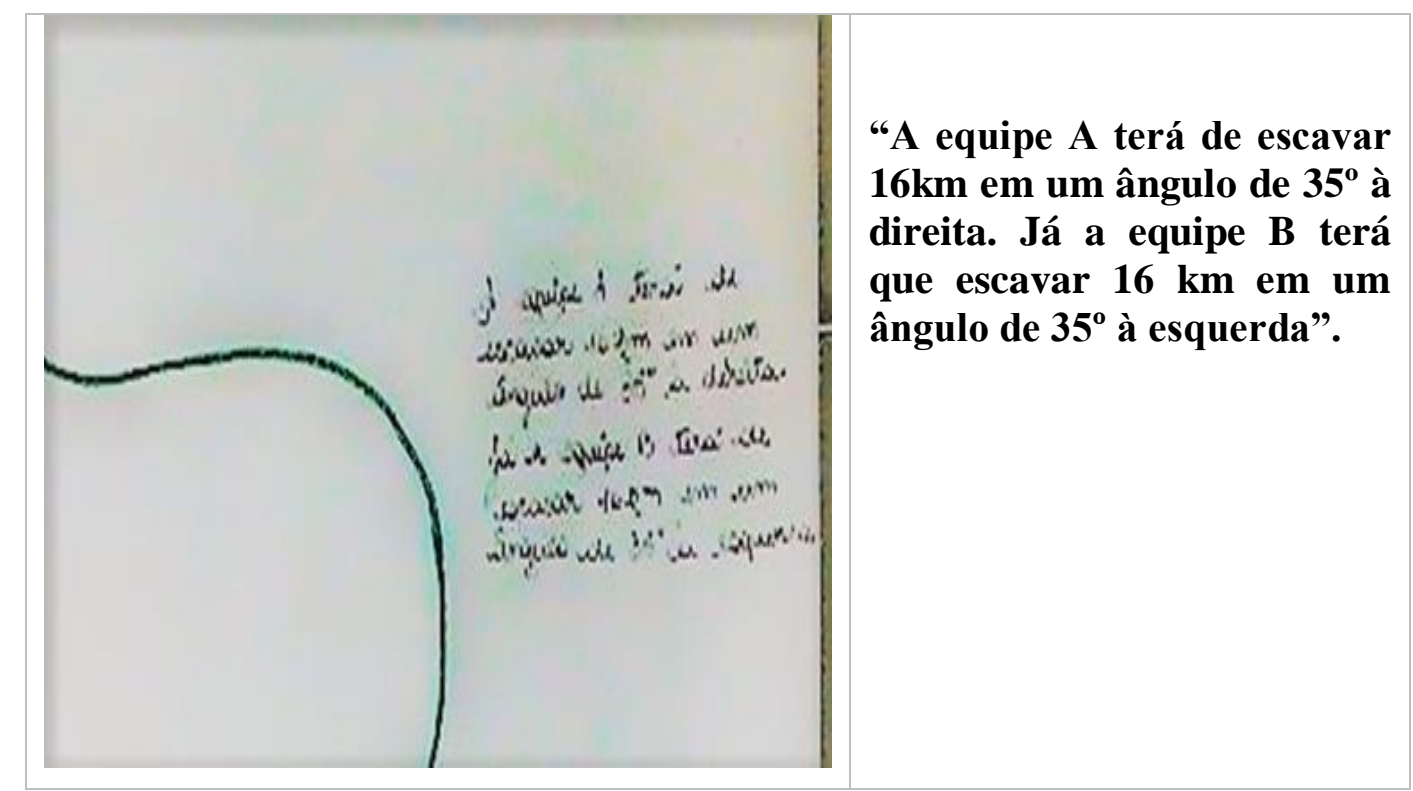

Fonte: Dados da pesquisa.

Na sequência, propusemos aos alunos a socialização dos resultados obtidos para que analisassem as estratégias desenvolvidas por eles e pelos demais grupos, e pudessem verificar a validade dos argumentos construídos e os possíveis erros cometidos.

Durante a socialização dos resultados, constatamos que os alunos perceberam a necessidade da generalização das ideais matemáticas e reconheceram a importância do conhecimento científico como forma de preencher o sentido das ideias trabalhadas.

Observamos, nessa etapa, que embora as estratégias utilizadas por todos os grupos para solucionar a situação proposta fossem as mesmas, cada grupo distinguiu sua referência espacial com base na localização dos pontos que haviam fixado nas extremidades da montanha. 
Figura 5: Estratégias apresentada pelo grupo 02

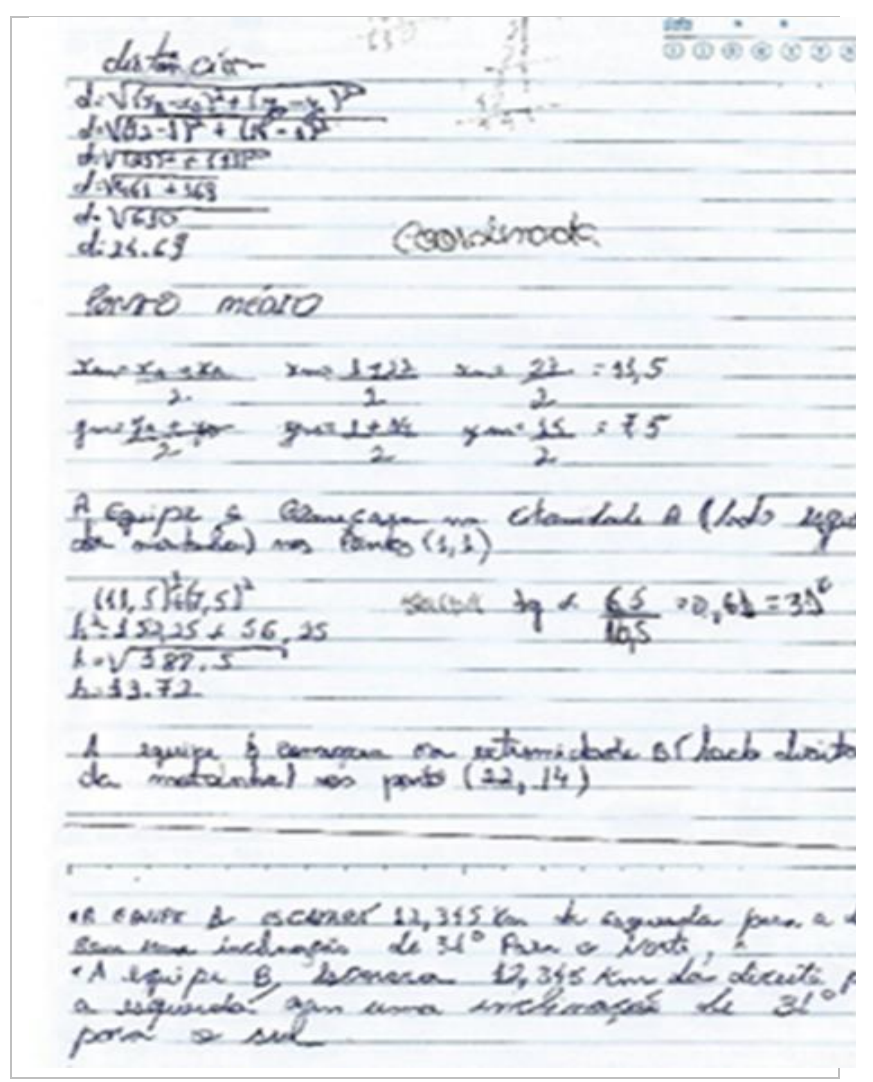

Fonte: Dados da pesquisa.

Notamos que, enquanto os alunos do grupo 02 buscavam descrever com palavras todos os procedimentos necessários para que as equipe " $\mathrm{A}$ " e "B" efetuassem as escavações, nos outros dois argumentos construídos (grupo 03 e grupo 04) os alunos limitaram-se apenas em apresentar as operações matemáticas que realizaram para chegar à conclusão apresentada.

Figura 6: Estratégias apresentadas, respectivamente, pelos grupos 03 e 04
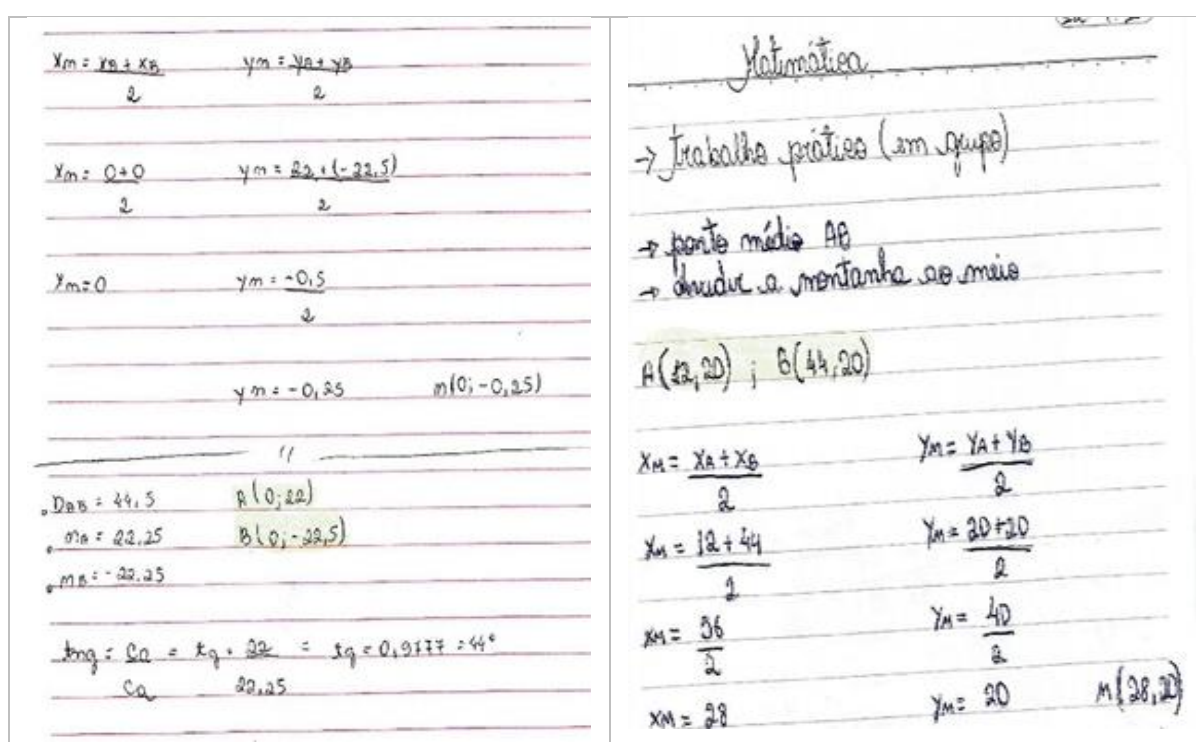
Para Lakatos (1978) essas contradições apresentadas são favoráveis para o crescimento do conhecimento matemático do aluno. Segundo o pesquisador, "o ponto de partida para todo processo de desenvolvimento matemático é encontrado na experiência que uma contradição pode proporcionar" (LAKATOS, 1978, p.45).

Figura 7: Comentário feito pelo aluno Y em relação à atividade desenvolvida

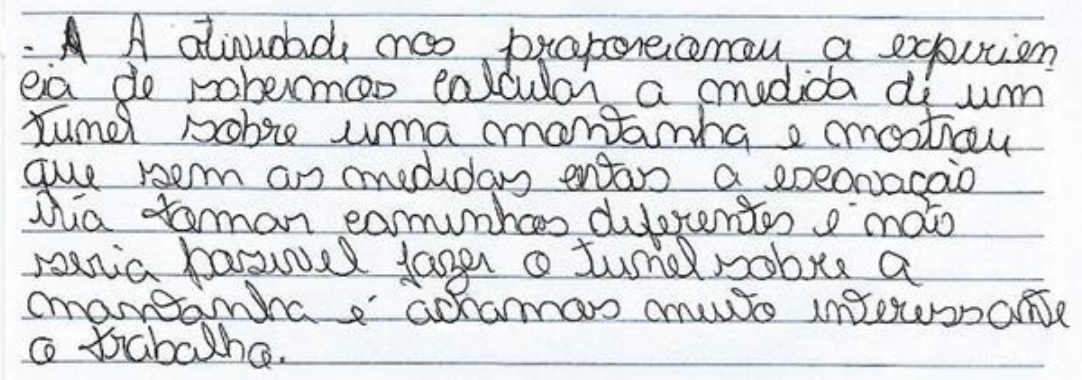

Fonte: Dados da pesquisa.

É importante destacarmos que a proposta de trabalho aqui apresentada valoriza o raciocínio e estimula o interesse do aluno, como pode ser comprovado pelo comentário feito pela aluna "B" a respeito da atividade realizada (FIGURA 08).

Figura 8: Comentário da aluna "B" do $3^{\circ}$ ano A

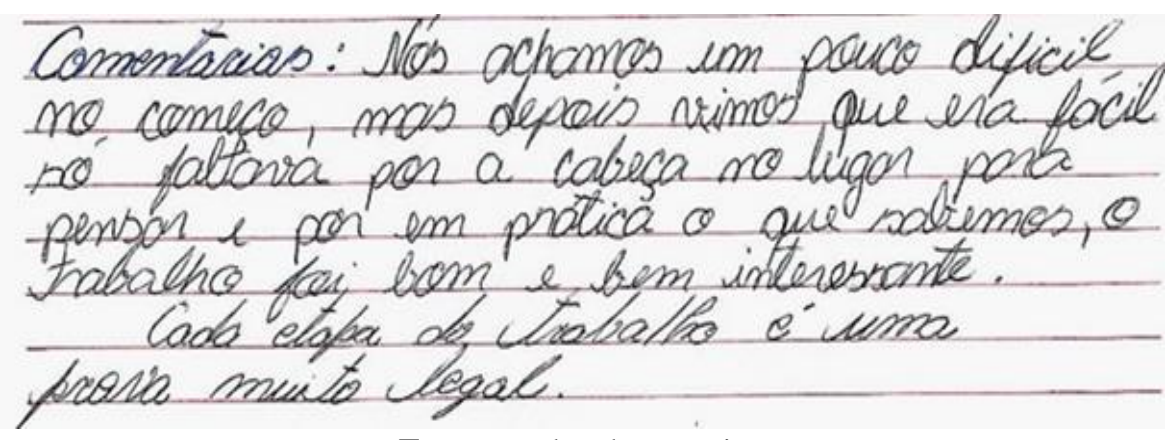

Fonte: Dados da pesquisa.

Dessa forma, acreditamos que o experimento desenvolvido deu ênfase à comunicação de ideias e à contínua construção do conhecimento matemático produzido. Percebemos, nas interações entre os alunos e nas exposições de ideias e estratégias apresentadas durante o desenvolvimento do experimento, uma crescente autonomia intelectual e crítica.

\section{Considerações finais}

A ideia de seguir o paradigma de uma aprendizagem centrada em conteúdos e premida pela necessidade de medir de forma objetiva o "sucesso" ou "fracasso" da matemática escolar é deixar de lado aspectos importantes que envolvem todo esse processo educacional. A 
aprendizagem é condição necessária e essencial do desenvolvimento potencial do sujeito e tem influência direta no processo de construção do seu conhecimento.

Ao iniciarmos essa pesquisa investigando o processo de construção do pensamento Geométrico, chegamos à reflexão de que as diversas mudanças ocorridas na estruturação desse conhecimento, em um espaço de tempo tão curto, acarretou uma inesperada rebelião intelectual, mudando de maneira significativa a forma do indivíduo ver o mundo.

A visão de mundo que relacionava determinados fatos ou acontecimentos à intuição humana, variando de acordo com as condições vivenciadas por um indivíduo ou por grupos de indivíduos, deu lugar a um conhecimento estruturado na conceitualização do espaço processada e organizada de forma lógica e sistematizada.

Encontramos nas civilizações antigas indícios de que a Geometria não reside apenas no espaço físico, mas possui também um enorme caráter abstrato, ou seja, de uma ciência que demonstra que a precisão de suas previsões é bem maior que os seus resultados observacionais.

Pensando na evolução histórica da humanidade, considerando que o nosso conhecimento começa com as experiências vividas e que nossa percepção acerca do universo está relacionada à maneira pela qual associamos o mundo às nossas ideias, entendemos que a grandeza da Geometria revela-se na sua singular habilidade de juntar tudo na forma de uma teoria e na insistência de fornecer uma demonstração para as consequências dela.

Nesse sentido, ao analisarmos os dados obtidos na pesquisa, não nos objetivamos apenas em obter uma resposta única para as questões aqui apresentadas, mas, sim, em investigar criteriosamente qual contribuição esse processo de "Prova Experimental" traz para a Educação Matemática.

Sabemos que existem muitos exemplos de recursos didáticos que favorecem a construção de conceitos e propriedades geométricas, contudo, optamos por propor uma atividade de "Prova Experimental". Isso se deu por considerarmos que essa estratégia de ensino contempla um olhar reflexivo sobre a ação pedagógica, tanto em seus aspectos cognitivos como didáticos.

Buscamos, com a construção dessa atividade de "Prova Experimental", mostrar que é possível produzir atividades investigativas com recursos que estão ao alcance do professor na sala de aula.

Ao analisarmos, de forma geral, os argumentos construídos pelos sujeitos envolvidos na pesquisa, verificamos que as construções de pensamento apresentadas, concentram-se em um nível de "Prova Pragmática" classificada como "Empirismo Ingênuo". 
Percebemos, na maioria das vezes, que as justificativas sobre o fato observado são construídas com base na apresentação de um caso particular ou por meio de imagens. Isso não quer dizer que os argumentos construídos não apresentaram experiências de pensamento construtivas.

Notamos, na atividade desenvolvida, estratégias "engenhosas", capazes de abordar diversos aspectos importantes do problema apresentado. Por esse motivo, entendemos que a atividade de "Prova Experimental" aqui proposta é capaz de auxiliar, de forma significativa, na construção de um pensamento geométrico mais avançado.

\section{Referências}

ALVES, José Pinho. Atividade experimental: uma alternativa na concepção construtivista. In: Encontro de Pesquisa e Ensino de Física, 8. 2002, Águas de Lindóia. Anais ... São Paulo: SBF, p. 120,2002 .

ARISTÓTELES. Segundos Analíticos. Livro II. Tradução de Lucas Angioni. Cadernos de Tradução ño. 4, Campinas: Instituto de Filosofia e Ciências Humanas/ Unicamp, 2004. (Coleção Clássicos da Filosofia).

BALACHEFF, Nicolas. Processus de preuve et situations de validation. Educational Studies In Mathematics. In: International Journal. v. 2, n. 18, p.147-176, maio 1987.

BICUDO, Maria Aparecida Viggiani (Org.). Filosofia da educação matemática: fenomenologia, concepções, possibilidades didático-pedagógicas. São Paulo: UNESP, 2010.

BOYER, Carl Benjamin. História da matemática. 2. ed. Tradução Elza F. Gomide. São Paulo: Edgard Blucher, 1996.

CHAUÍ, Marilena. Convite à filosofia. São Paulo: Ática, 2000.

CHAUÍ, Marilena. A Filosofia: ética ou filosofia moral. In: CHAUI, Marilena. Convite à filosofia. São Paulo: Ática, 1995. p. 339-356.

DESCARTES, René. Discurso sobre o método. Tradução: Maria Hermantina Galvão. São Paulo: Martins Fontes, 2001.

FERREIRA, Aurélio Buarque de Holanda. Referência. In: FERREIRA, Aurélio Buarque de Holanda. O mini dicionário da língua portuguesa. 8 ed. rev. e ampl. Rio de Janeiro: Saraiva, 2010.

FETISSOV, A. I. A demonstração em geometria. Tradução Hygino H. Domingues. São Paulo: Atual, 1994.

HANNA, Gila. Proof, explanation and exploration: an overview. Educational studies in mathematics. Canadá, v. 44, n. 1, p.5-23, 2000.

IEZZI, Gelson; DOLCE Osvaldo; DEGENSZAJN, David; PÉRIGO, Roberto; ALMEIDA, Nilze de. Matemática: ciências e aplicações. v. 3. Ensino Médio, 8.ed. São Paulo: Atual, 2014.

KANT, Imannuel. Crítica da razão pura. 5.ed. Tradução J. Rodrigues de Merege. Lisboa: Fundação Calouste Gulbenkian, 2001. 
LAKATOS, Imre. A lógica do descobrimento matemático: provas e refutações. Tradução Nathanael C. Caixeiro. Rio de Janeiro: Zahar Editores, 1978.

MARK, Julian Cass. A Teoria da Prova em Leibniz. v. 11, n. 2, São Paulo: Scientia e studia, p. 79 $267,2013$.

MINAS GERAIS - Secretaria de Estado de Educação. CBC Matemática - Ensinos fundamental e médio. Disponível em: http:// www.educacao.mg.gov.br. Acesso em: 03/02/2016.

NASSER, Lilian; A TINOCO, Lucia A de. Argumentação e provas no ensino de matemática. Rio de Janeiro: UFRJ/Projeto Fundão, 2003.

PIAGET, Jean. O desenvolvimento do pensamento: equilibração das estruturas cognitivas. Lisboa: Dom Quixote, 1977.

PLATÃO. A República. Tradução Enrico Corvisiere. São Paulo: Nova Cultura, 2000.

ROONEY, Anne. A História da Matemática. Brasil: M Books, 2012.

VYGOTSKY, Lev Semenovich. Pensamento e linguagem. Rio de Janeiro: Martins Fontes, 1998.

Recebido em 25/08/2017 - Aceito em 31/10/2017 